\title{
Combination of wound healing with 1-methylcyclopropene and wound detection by iodine solution to maintain the quality of sweet potato during long-term storage
}

\author{
Jixuan Cao, Pei Liu, Xuejiao Wang, Qingguo Wang, Jingying Shi* \\ (Key Laboratory of Food Processing Technology and Quality Control in Shandong Province, \\ College of Food Science and Engineering, Shandong Agricultural University, Tai'an 271018, Shandong, China)
}

\begin{abstract}
Wound healing treatment after harvest is a critical step to protect sweet potatoes from pathogens. The method of phloroglucinol staining is commonly used for detecting callus. However, this method is not easy to identify the degree of callus as the color change is not obvious compared with non-curing roots for some cultivars. A new method based on the principle of starch test by iodine was developed for the detection of wound healing. After healing, the reducing sugar content increased while the starch content decreased to a lower level compared to that of the non-curing roots. Moreover, the antioxidant capacity of the sweet potato after wound healing was higher than that in the control. Wound healing combined with ethylene, 1-methylcyclopropene (1-MCP), chlorpropham or abscisic acid were studied for inhibiting sprout of sweet potato root caused by high temperature during curing. The results showed ethylene and 1-MCP treatment had no negative effect on wound healing. Moreover, 1-MCP treatment was the most effective one on the suppression of sprouting and decay of sweet potato. The results indicate that iodine solution staining is a useful and rapid method to identify the wound healing extent, and 1-MCP treatment can effectively inhibit root sprouting during wound healing and the subsequent long-term storage.

Keywords: sweet potato, wound healing, iodine staining, sprouting inhibition, decay rate

DOI: $10.25165 /$ j.ijabe.20211403.5735
\end{abstract}

Citation: Cao J X, Liu P, Wang X J, Wang Q G, Shi J Y. Combination of wound healing with 1-methylcyclopropene and wound detection by iodine solution to maintain the quality of sweet potato during long-term storage. Int J Agric \& Biol Eng, 2021; 14(3): 241-246.

\section{Introduction}

Sweet potato (Ipomoea batatas L.), a nutrient-rich root crop, is widely planted and has a high production level in China. Sweet potato is an excellent source of enriched fibers, minerals, antioxidant compounds and other nutritional and functional ingredients ${ }^{[1-3]}$. After harvest, sweet potato can only be stored at relatively high temperatures for a long time which is not below $10^{\circ} \mathrm{C}$; otherwise, chilling injury symptoms would appear quickly. Therefore, it is a challenge to maintain the quality of sweet potato during its long-term storage. In addition, sweet potato is likely to get wounded during harvest, transport, and preparation for storage $^{[4]}$. If the damaged skin of sweet potato could not become dry immediately, the root becomes susceptible to fungus and bacteria thus sharply increasing the decay rate; and the enhanced respiration rate by the mechanical injury would further cause greater loss. Therefore, it is essential to heal the wound before

\section{Received date: $2020-02-16 \quad$ Accepted date: $2020-08-28$}

Biographies: Jixuan Cao, Master candidate, research interest: post-harvest storage and preservation of fruits and vegetables, Email: 1093546410@qq.com; Pei Liu, PhD, Lecturer, research interest: post-harvest storage and preservation of fruits and vegetables, Email: liupei83224@163.com; Xuejiao Wang, Master, research interest: post-harvest storage and preservation of fruits and vegetables, Email: 693836995@qq.com; Qingguo Wang, PhD, Professor, research interest: post-harvest storage and preservation of fruits and vegetables, Email: wqgyyy@126.com.

*Corresponding author: Jingying Shi, PhD, Professor, research interest: post-harvest storage and preservation of fruits and vegetables. College of Food Science and Engineering, Shandong Agricultural University, Tai'an 271018, Shandong, China. Tel: +86-538-8245855, Email: jyshi80@163.com. storage for many roots and tubers to reduce their decay during storage $^{[5,6]}$. Phloroglucinol staining is a popular method for detecting the curing extent of sweet potato, since lignin in plant cell wall can be stained by phloroglucinol in the presence of alcohol and hydrochloric acid $(\mathrm{HCl})$. If the wound are healing under a suitable condition, the skin in the outer layer of the wound will be covered with lignin which will show pink color due to phloroglucinol staining ${ }^{[7]}$. However, it might not be so easy to discern whether the wounds of roots are healed well or not because the root color of some cultivars after being cured and stained may be similar to the skin of sweet potatoes. So, it is highly desired to develop novel techniques to clearly determine the proper period of the wound healing process. Additionally, it is also valuable to perform systematic study on curing conditions as well as nutrition changes during the storage of sweet potato roots so that corresponding strategies could be taken to reduce industry loss.

It's reported that different cultivars require varied optimal healing times and/or temperatures ${ }^{[8]}$. However, little research has been performed to handle some new cultivars of sweet potato in China. Even though wound healing is a useful method to reduce moisture loss and the decay rate of stored sweet potatoes, poor curing conditions would promote sprouting percentage as wound healing is often conducted at relatively high temperature such as $85^{\circ} \mathrm{F}\left(29^{\circ} \mathrm{C}\right)$ and high relative humidity (RH) of $90 \%$ with proper ventilation for 3-5 d immediately after harvest ${ }^{[9]}$. Therefore, an effective method should be considered to overcome this problem. Chlorpropham (CIPC) is commonly applied to potatoes before or during their storage to suppress sprouting. It has been reported that CIPC can also suppress the sprouting of sweet potatoes to some extent ${ }^{[10]}$. However, considering the safety of CIPC, 
alternatives such as ethylene and 1-methylcyclopropene (1-MCP) have been tested to inhibit sprout growth and sprouting in some dormancy roots ${ }^{[11,12]}$. However, it is not yet known whether these methods can effectively suppress sprouting or have a negative effect on wound healing in sweet potatoes.

Even though a good curing condition is useful for restricting pathogen infection, the decay rate keeps at a high level during long storage. Now, the fungicides such as iprodione or chlorothalonil have been commonly used for the control of postharvest sweet potato decay in China. So an effective and safe method should be developed to maintain good quality and reduce the loss of sweet potatoes.

In this study, a new curing method was proposed for two popular varieties of sweet potatoes in China, the curing time and temperature were optimized to prevent the decay of damaged sweet potato, and the influence of wound healing on the quality of postharvest sweet potato was studied. In addition, some growth regulators were selected to repress the sprouting and decay caused by the high temperature during wound healing.

\section{Materials and methods}

\subsection{Sweet potato}

Yellow-fleshed (Beijing 553) and purple-fleshed (Chuanshanzi) sweet potato roots were provided by the Yantai Academy of Agricultural Science. Both cultivars of sweet potatoes were collected from Donghu Village, Anzhan Town, Feicheng City, Shandong Province. The roots were collected in October, and then transported to the Postharvest Laboratory of Fruits and Vegetables of Shandong Agricultural University. Roots with uniform size and shape, and without any visual defect were selected for the research.

\subsection{Comparison of two detection methods for wound healing assay}

The purple-fleshed (Chuanshanzi) cultivar of sweet potato roots was used for curing detection with both phloroglucinol and iodine staining methods. The roots were divided into two groups randomly and the skin of the roots was intentionally scraped with a knife. Each group included 30 roots with 3 repetitions. One group of the roots were directly stored in a storage room at $(13 \pm 0.5)^{\circ} \mathrm{C}, \mathrm{RH} 90 \%$. The other group was cured at $29^{\circ} \mathrm{C}, \mathrm{RH}$ $90 \%-95 \%$ for $4 \mathrm{~d}$ and then stored in a storage room at $(13 \pm 0.5)^{\circ} \mathrm{C}$, RH 90\%. Two staining solutions including iodine and phloroglucinol were separately prepared and one drop of the iodine solution was spread on the scraped skin on the 4th day. The traditional method of phloroglucinol staining was conducted following the method of Jensen ${ }^{[7]}$ with some modifications. First, a saturated solution of phloroglucinol with $20 \% \mathrm{HCl}$ was prepared in the fume hood. About $2.0 \mathrm{~g}$ phloroglucinol (purchased from Sigma) was firstly dissolved in $80 \mathrm{~mL} 20 \%$ ethanol-water solution (V/V) followed by adding $20 \mathrm{~mL}$ of concentrated $\mathrm{HCl}(12 \mathrm{~mol} / \mathrm{L})$ to it. The solution was filtered to remove crystals then stored in a reagent bottle. The iodine solution was prepared in deionized water by dissolving iodine and potassium iodide at the ratio of 1:2 (w/w). A few (2-3) drops of the staining solutions were respectively applied to a scraped surface of sweet potatoes. After $1 \mathrm{~min}$, the phloroglucinol or iodine solutions were absorbed with a piece of absorbent paper. Finally, the color of the wounding site was measured.

2.3 Measurement of the curing days and temperatures

The yellow-fleshed (Beijing 553) and purple-fleshed (Chuanshanzi) cultivars of sweet potato roots were used for determining the suitable wound healing days and temperatures. Four groups of roots were included and each group including 30 roots with 3 repetitions were stored in a storage room (RH 90\%), but at various temperatures and different days including $(13 \pm 0.5)^{\circ} \mathrm{C}$, $(20 \pm 0.5)^{\circ} \mathrm{C},(25 \pm 0.5)^{\circ} \mathrm{C}$ and $(29 \pm 0.5)^{\circ} \mathrm{C}$, for $4 \mathrm{~d}, 6 \mathrm{~d}, 8 \mathrm{~d}, 10 \mathrm{~d}$ and $12 \mathrm{~d}$, respectively. Then, iodine and phloroglucinol solutions were separately applied simultaneously for detecting the proper curing temperatures. Color score was used for presenting color development of the wound. For phloroglucinol dying, the method of Walter et al. ${ }^{[13]}$ was used with slight modifications, where $0=$ no discoloration, $1=$ pink, $2=$ red, and $3=$ reddish to purple. For iodine dying, the classification criteria were as follows: 0 '=black blue, 1 '=blue, 2'=weak blue, and 3 '=no discoloration.

\subsection{Detection of the quality effect of wound healing}

2.4.1 Measurement of sprouting rate, decay index and decay rate

The cultivars of Chuanshanzi were used for the experiment. During storage, the sprouting rate (\%) was calculated by the following equation.

$$
\text { Sprouting rate }=\frac{\text { number of sprouting roots }}{\text { number of all the investigated tubers }} \times 100 \% \text { (1) }
$$

Disease development was evaluated by measuring the decay area every two months. Disease severity in terms of decay area was classified as 6 grades (0-5), where $0=$ without decay; $1=$ less than $10 \%$ decay area; $2=10 \%-30 \%$ decay area; $3=30 \%-50 \%$ decay area; $4=50 \%-70 \%$ decay area; $5=$ over $70 \%$ decay area. These empirical scales made it possible to calculate the decay index showing the average of the disease severity.

Decay index $=$

$$
\frac{\sum(\text { decay grade } \times \text { number of this grade })}{\text { total number of investigated tubers } \times \max \text { imum decaygrade }} \times 100 \%
$$

The decay rate of the sweet potato was assessed by measuring the extent of the total decay area of the root. The decay rate was calculated by the following equation.

$$
\text { Decay rate }=\frac{\text { number of disease tubers }}{\text { number of investigated tubers }} \times 100 \%
$$

\subsubsection{Detection of the content of reducing sugar and starch}

The reducing sugar content was determined by using the 3 , 5-dinitrosalicylic acid method ${ }^{[14]}$. Starch content was measured following the method of Dandago et al. ${ }^{[15]}$

2.4.3 Measurement of the antioxidant capacity

The antioxidant capacity was determined by 1,1-diphenyl-2-picrylhydrazyl (DPPH) inhibition rate ${ }^{[16]}$ with some modifications. Sweet potato powder $(2.0 \mathrm{~g})$ was mixed with $8 \mathrm{~mL}$ acetone and then incubated in an incubator (Ningbo Dongnan Instrument Co., Ltd., China). Two grams of ground sweet potato powder was mixed with $10 \mathrm{~mL}$ ethanol and centrifuged at $10000 \times \mathrm{g}$, then $1.0 \mathrm{~mL}$ of the supernatant was mixed with $2.5 \mathrm{~mL}$ of the DPPH solution, and the mixture was incubated at room temperature for $30 \mathrm{~min}$. The mixture of $2.5 \mathrm{~mL} \mathrm{DPPH}$ solution and $1.0 \mathrm{~mL} 95 \%$ ethanol solution was as the blank. The absorbance was determined at $517 \mathrm{~nm}$.

2.5 Measurement of the role of CIPC, ethylene, 1-MCP and ABA during wound healing treatment and long-time storage

Slow-released ethephon (5\% solid ethephon powder/sachet, $0.3 \mathrm{~g} / \mathrm{sachet})$ and 1-MCP $(0.045 \%$ 1-MCP cyclodextrin powder, $0.4 \mathrm{~g} / \mathrm{sach}$ ) $)$ were supplied by Shandong Yingyangyuan Food Technology Co., Ltd (Shandong, China). Sweet potato roots (approximately $100 \mathrm{~kg}$ ) were divided into 5 groups randomly. One group of roots was treated with $50 \mathrm{mg} / \mathrm{L}$ abscisic acid (ABA) 
solution for 5 min then stored in a sealed case at $29^{\circ} \mathrm{C}$ for $4 \mathrm{~d}$. The other three groups of roots were treated with $10 \mathrm{mg}$ CIPC per kilogram fresh weight, slow-released 1-MCP (4 sachets/case), slow-released ethylene ( 4 sachets/case) in sealed cases at $29^{\circ} \mathrm{C}$ for $4 \mathrm{~d}$, respectively. Roots of the last group, as the control, were not treated but stored in a sealed case at $29^{\circ} \mathrm{C}$ for $4 \mathrm{~d}$. After $4 \mathrm{~d}$, the roots curing in the cases were removed from the cases and stored at $(13 \pm 0.5)^{\circ} \mathrm{C}$. The effect of different treatments on iodine staining and the rates of sprouting and decay were investigated after the storage of 3,5, 7 and 9 months. The experiments were repeated three times for statistical purposes.

\subsection{Statistical analysis}

The experiments were performed in triplicates. Data were analyzed by SPSS 20.0 Windows Software (SPSS Inc., Chicago, USA) and presented as means \pm standard errors (S.E.). One-way analysis of variance (ANOVA) was used for data analysis and Tukey analysis was used to compare treatment means at the 5\% level.

\section{Results and discussion}

\subsection{Comparison of appearance color after staining with different reagents}

After harvest, the sweet potato roots were fresh thus easy to be wounded. After being stained with phloroglucinol solution, the flesh with the wound appeared red-violet on the wound surface of curing roots, but there was no discoloration on the surface of the control roots (Figure 1b). Oppositely, if the staining of iodine solution was used, the wound surface had no obvious discoloration on the wound healing roots, but a deep blue color appearing on the control (Figure 1a)

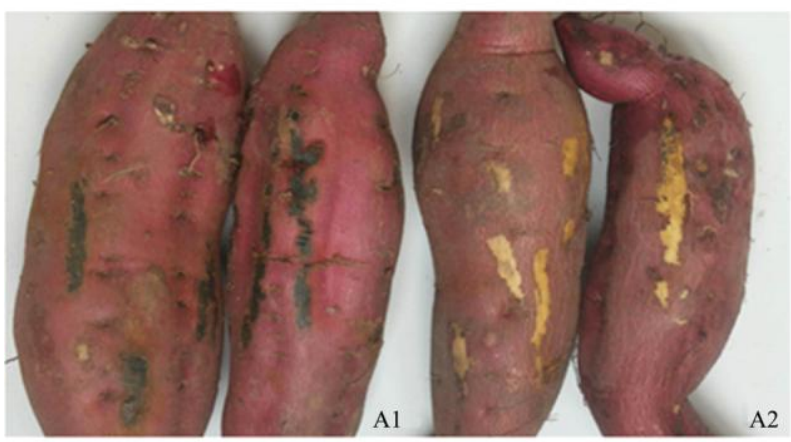

a. Iodine solution (A1, without curing; A2, after curing)

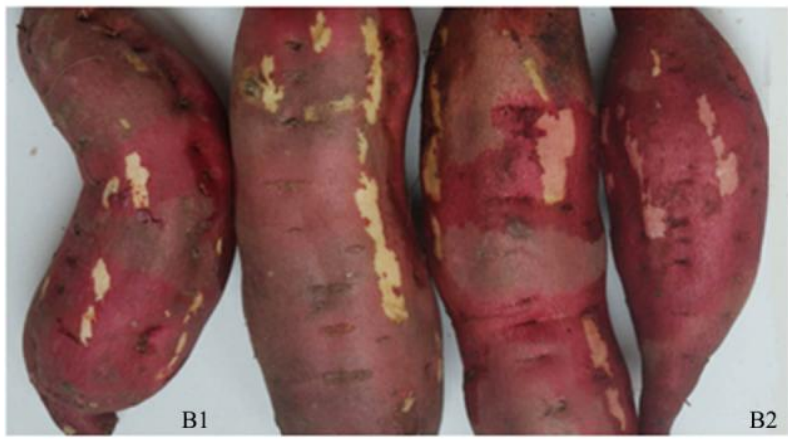

b. Phloroglucinol solution (B1, without curing; B2, after curing)

Figure 1 Detection of wound healing extent by two dye reagents for the purple category (Chuanshanzi) of sweet potato cured at $29^{\circ} \mathrm{C}$ for $4 \mathrm{~d}$

Even though the red-violet color is more obvious than that in the control, the color is a little weak, especially for some purple peel cultivars. During wound healing, starch in the wound will gradually be expended as the respiration rate is very high. By the principle of starch turning blue when exposed to iodine, the root of non-healing can be identified. The color change in the process of wound healing is very clear. So, this method can be used as a criterion to tell whether the curing is completed or not before the long-term storage of some root or tuber vegetables.

3.2 Effects of different time and temperatures on the wound healing of sweet potatoes

It has been reported that wound healing of potato tubers goes faster at high temperatures $\left(<30^{\circ} \mathrm{C}\right)$ and in high moisture, and the effect of temperature is more critical in the wound healing process $^{[17]}$. When the roots were exposed to temperatures of $28-30^{\circ} \mathrm{C}$, wound healing in sweet potatoes was the most efficient ${ }^{[10]}$ The present results showed the sweet potato wounds of the two cultivars could not be stained by the phloroglucinol solution at relatively low temperatures such as $13^{\circ} \mathrm{C}$ even after curing for $12 \mathrm{~d}$ (Table 1). At $25^{\circ} \mathrm{C}$, more days were needed for wound healing compared with the roots at $29^{\circ} \mathrm{C}$. So, appropriate temperature and time are key factors affecting the wound healing process. For 'Beijing 553', the roots were stored at $25^{\circ} \mathrm{C}$ for $8-12 \mathrm{~d}$ or $29^{\circ} \mathrm{C}$ for 4-12 d, the wound periderm would be formed completely. For 'Chuanshanzi', the roots were stored at $25^{\circ} \mathrm{C}$ for $6-12 \mathrm{~d}$ or $29^{\circ} \mathrm{C}$ for 4-12 d, the wounds would be healed. Therefore, the optimal wound healing conditions vary for different cultivars.

Table 1 Curing temperature screening of two cultivars of sweet potato using staining method at the condition of RH $90 \%$

\begin{tabular}{|c|c|c|c|c|c|c|c|c|c|}
\hline \multirow{2}{*}{ Cultivars } & \multirow{2}{*}{$\begin{array}{l}\text { Curing } \\
\text { days/d }\end{array}$} & \multicolumn{4}{|c|}{$\begin{array}{l}\text { Iodine solution staining at } \\
\text { different temperatures }\end{array}$} & \multicolumn{4}{|c|}{$\begin{array}{l}\text { Phloroglucinol staining at } \\
\text { different temperatures }\end{array}$} \\
\hline & & $13^{\circ} \mathrm{C}$ & $20^{\circ} \mathrm{C}$ & $25^{\circ} \mathrm{C}$ & $29^{\circ} \mathrm{C}$ & $13^{\circ} \mathrm{C}$ & $20^{\circ} \mathrm{C}$ & $25^{\circ} \mathrm{C}$ & $29^{\circ} \mathrm{C}$ \\
\hline \multirow{5}{*}{ Beijing 553} & 4 & $3^{\prime}$ & $3^{\prime}$ & 2 ' & 0 , & 0 & 0 & 1 & 3 \\
\hline & 6 & $3^{\prime}$ & $3^{\prime}$ & 1 ' & 0 ' & 0 & 0 & 2 & 3 \\
\hline & 8 & 3, & 2 ' & 0 , & $0^{\prime}$ & 0 & 1 & 3 & 3 \\
\hline & 10 & 3, & 2 ' & 0 , & 0 , & 0 & 2 & 3 & 3 \\
\hline & 12 & $3^{\prime}$ & 1 ' & $0^{\prime}$ & 0 ' & 0 & 3 & 3 & 3 \\
\hline \multirow{5}{*}{ Chuanshanzi } & 4 & $3^{\prime}$ & $3^{\prime}$ & 1 ' & 0 ' & 0 & 0 & 2 & 3 \\
\hline & 6 & $3^{\prime}$ & 3 ' & $0^{\prime}$ & 0 ' & 0 & 0 & 3 & 3 \\
\hline & 8 & 3, & 2 & 0 , & $0^{\prime}$ & 0 & 1 & 3 & 3 \\
\hline & 10 & $3^{\prime}$ & 1 ' & 0 ' & 0 ' & 0 & 2 & 3 & 3 \\
\hline & 12 & $3^{\prime}$ & 1 ' & 0 , & 0 , & 0 & 3 & 3 & 3 \\
\hline
\end{tabular}

Note: " $0,1,2,3$ " indicate the extent of sweet potato roots stained by phloroglucinol solution, where 0 represents no discoloration, 1 represents pink, 2 represents red, and 3 represents reddish to purple. ' 0 ', 1', 2', 3'" indicate the extent of sweet potato roots stained by iodine solution, where 0 ' represents black blue, 1' represents blue, 2' represents weak blue, and 3' represents no discoloration.

\subsection{Effect of different curing time at $29^{\circ} \mathrm{C}$ on the decay rate of sweet potatoes}

Compared with the direct storage at $(13 \pm 0.5)^{\circ} \mathrm{C}$ (without curing), curing for $4 \mathrm{~d}, 6 \mathrm{~d}, 8 \mathrm{~d}$ or $10 \mathrm{~d}$ reduced the decay rates of the sweet potatoes within 5 months storage (Table 2). Wound healing slowed down the rate of deterioration of sweet potato roots, and cured at $29^{\circ} \mathrm{C}$ for $4 \mathrm{~d}$ had the best effect on reducing decay rate during long-term storage. Placing roots at $29^{\circ} \mathrm{C}$ for more than $4 \mathrm{~d}$ not only had no effect on wound healing (Table 1), but also enhanced the decay rate of the roots during storage. The results indicate the roots should be moved to a relatively low temperature as soon as possible after the wound healing is completed at the high temperature. Edmunds et al. ${ }^{[9]}$ also suggests after curing, the sweet potato should be stored in the proper environment to maintain root quality. 
Table 2 Decay rate after stored different months at $(13 \pm 0.5)^{\circ} \mathrm{C}$ by curing different days at $29^{\circ} \mathrm{C} \mathrm{RH} 90 \%$ for Chuanshanzi sweet potato

\begin{tabular}{cccccc}
\hline \multirow{2}{*}{$\begin{array}{c}\text { Curing } \\
\text { days/d }\end{array}$} & \multicolumn{5}{c}{ Decay rate at different storage months/\% } \\
\cline { 2 - 6 } & 1 & 3 & 5 & 7 & 9 \\
\hline 0 & $11.8 \pm 3.1^{\mathrm{a}}$ & $22.5 \pm 2.3^{\mathrm{a}}$ & $45.1 \pm 4.0^{\mathrm{a}}$ & $61.2 \pm 4.7^{\mathrm{b}}$ & $71.4 \pm 5.2^{\mathrm{bc}}$ \\
4 & $3.0 \pm 1.6^{\mathrm{b}}$ & $10.8 \pm 3.2^{\mathrm{c}}$ & $27.8 \pm 4.5^{\mathrm{bc}}$ & $39.2 \pm 3.7^{\mathrm{c}}$ & $55.2 \pm 7.9^{\mathrm{d}}$ \\
6 & $0.0 \pm 0.0$ & $11.5 \pm 2.1^{\mathrm{b}}$ & $26.9 \pm 4.4^{\mathrm{c}}$ & $38.3 \pm 4.8^{\mathrm{c}}$ & $63.9 \pm 4.2^{\mathrm{c}}$ \\
8 & $0.0 \pm 0.0$ & $13.32 \pm 2.6^{\mathrm{b}}$ & $32.4 \pm 5.7^{\mathrm{b}}$ & $62.6 \pm 3.4^{\mathrm{b}}$ & $76.7 \pm 5.0^{\mathrm{b}}$ \\
10 & $0.0 \pm 0.0$ & $13.66 \pm 2.9^{\mathrm{b}}$ & $35.2 \pm 6.4^{\mathrm{b}}$ & $70.5 \pm 6.4^{\mathrm{a}}$ & $100.0 \pm 0.0^{\mathrm{a}}$ \\
\hline
\end{tabular}

Note: Sweet potatoes were callus treatments for $0 \mathrm{~d}, 4 \mathrm{~d}, 6 \mathrm{~d}, 8 \mathrm{~d}$, and $10 \mathrm{~d}$ at $29^{\circ} \mathrm{C}$, and then stored at $(13 \pm 0.5)^{\circ} \mathrm{C}$ for $1,3,5,7$, and 9 months before calculating the attenuation rate. The same letters in one column indicate no significant difference $(p>0.05)$.

\subsection{Effects of curing treatment on the content of reducing} sugar and starch

The contents of reducing sugar and starch demonstrated a similar trend in the curing-treated sweet potatoes and non-treated ones during the storage time (Figure 2a), but the roots with wound healing had significantly $(p<0.05)$ higher content of reducing sugar than the control, which was related to the higher respiration rate of the roots at $29^{\circ} \mathrm{C}$. On the contrary, the starch content of wound healed sweet potatoes was significantly $(p<0.05)$ lower than that of non-healed roots during the whole storage time (Figure $2 b$ ). Moreover, the starch contents in both curing treated and non-treated roots showed decreasing trends, which indicated that the starch was converted into simple sugars such as reducing sugars to maintain its storage life. A relationship of dry matter content in sweet potato roots, both in terms of shelf-life and wound-healing efficiency, has been reported previously ${ }^{[8,18]}$. Generally, lower dry matter content is associated with longer shelf-life and more efficient healing at low humidity ${ }^{[19]}$. Starch, one component of dry matter, showed a lower level in wound healing sweet potatoes, which benefited for the roots to have a longer storage life.

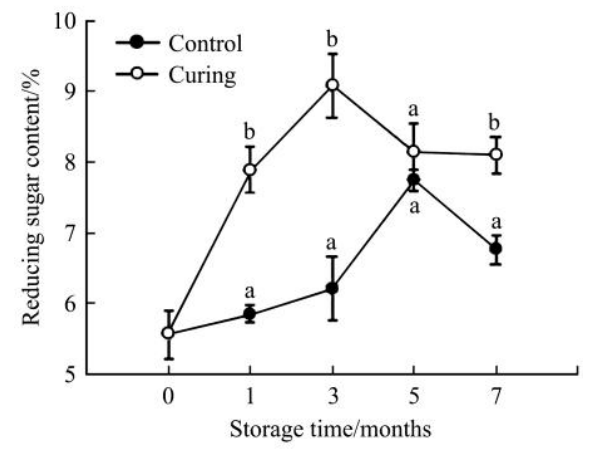

a. Reducing sugar

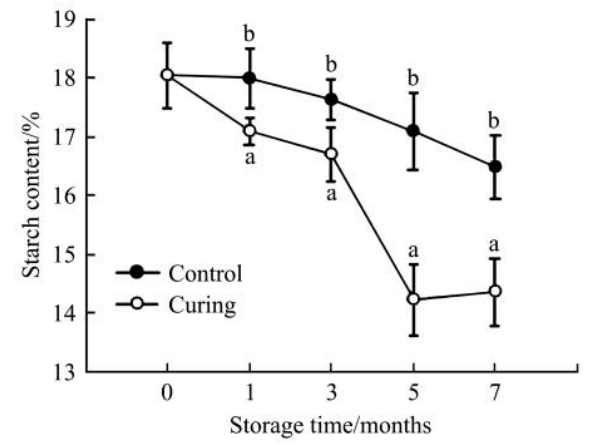

b. Starch

Note: Different letters in the same month mean the difference is significant $(p<0.05)$.

Figure 2 Effects of $29^{\circ} \mathrm{C}$ curing treatment on the content of reducing sugar and starch of the sweet potato during storage at $(13 \pm 0.5)^{\circ} \mathrm{C}$
3.5 Effects of curing treatment on free radical scavenging capacity of sweet potato peel and flesh

Sweet potatoes are enriched in antioxidant compounds ${ }^{[20]}$. The purple-fleshed sweet potato genotypes have some functions such as antioxidant, radical-scavenging activity ${ }^{[21]}$, and antimutagenicity ${ }^{[22]}$. The percent DPPH inhibition of sweet potato peels continuously increased then decreased in both wound healing treated and non-treated roots during storage, but the percent inhibition of the treated group was significantly higher $(p<0.05)$ than that of the control after an equal storage period except one month in flesh (Figure 3), which might be attributed to the scavenging of radical oxygen species thus protecting cells of the $\operatorname{roots}^{[23]}$. Moreover, the DPPH scavenging activity in peel was higher than that in the flesh of the sweet potato. It was reported that DPPH radical scavenging activity decreased during the storage in four cultivars of sweet potatoes ${ }^{[24]}$. However, in this experiment, the DPPH inhibition rate increased and then decreased during the storage, but wound healing could maintain a higher level of DPPH inhibition rate than no wound healing.
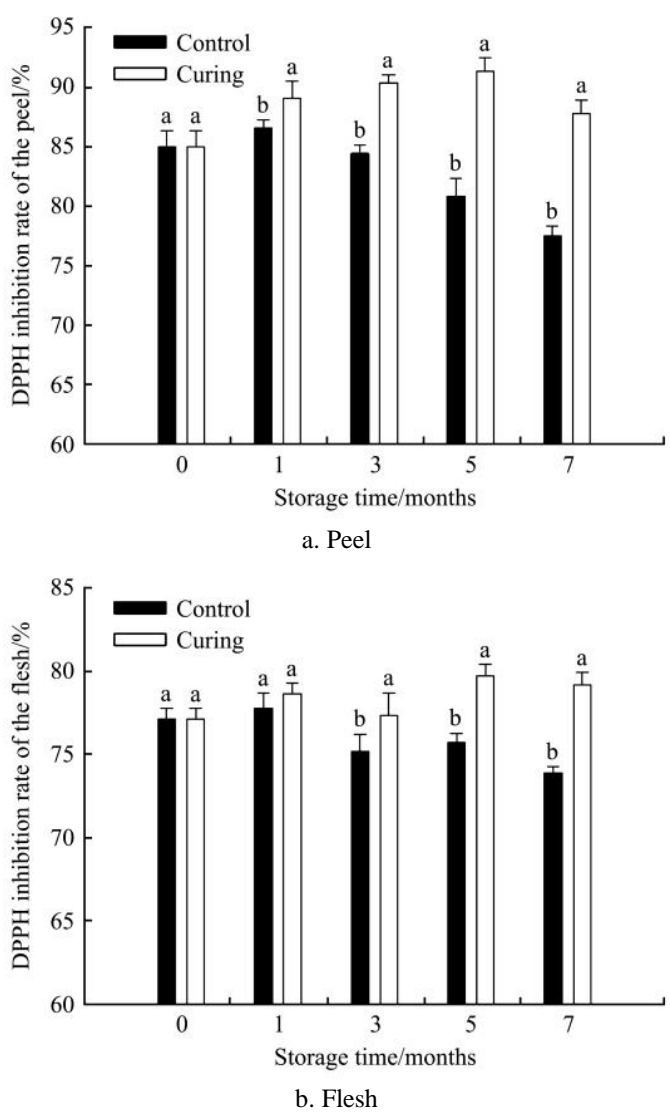

Note: Different letters in the same month mean the difference is significant $(p<0.05)$.

Figure 3 Effects of $29^{\circ} \mathrm{C}$ curing treatment on DPPH inhibition rate of peel and flesh of the sweet potato during storage at $(13 \pm 0.5)^{\circ} \mathrm{C}$

3.6 Effects of different growth regulators combined with curing at $29^{\circ} \mathrm{C}$ on the sprouting rate of sweet potato

As sprouting is an important problem that easily occurs after wound healing at high temperatures, growth regulators including ethylene, 1-MCP, CIPC and ABA were used during wound healing for inhibiting the sprouting. Compared to the treatment of curing at $29^{\circ} \mathrm{C}$ for $4 \mathrm{~d}$, the combination of curing with ethylene, 1-MCP, $\mathrm{CIPC}$ or $\mathrm{ABA}$ could reduce the sprouting rate during the storage (Table 3). It has demonstrated that continuous ethylene supplementation can suppress the sprouting of onion, potato and sweet potato $^{[11,12,25]}$. Onion treated with $1-\mathrm{MCP}$ can also suppress 
its sprout growth ${ }^{[11]}$. In potato tubers, ethylene is not part of the wound response required to initiate or modulate suberization or any of the closely associated processes ${ }^{[26]}$. Present results showed that continuous ethylene treatment had the best effect on inhibition of the sprouting rate, followed by CIPC and 1-MCP. However, the iodine staining on the surface of CIPC- and ABA-treated roots was deeper than that on ethylene- or 1-MCP-treated roots, which indicates that CIPC and ABA might have a negative effect on wound healing while inhibiting sprouting. ABA is a strong growth inhibitor of plants, which can inhibit seed germination. It is reported that $\mathrm{ABA}$ can inhibit axillary bud and root development and subsequent plantlet growth ${ }^{[27]}$, and the $\mathrm{ABA}$ content increasing may be a contributing factor to the extent of sprout suppression during exogenous ethylene treatment ${ }^{[11]}$. Exogenous ABA can stimulate suberization to accelerate curing in wounded kiwifruit and tomato fruit ${ }^{[28,29]}$. However, ABA could not accelerate wound healing of sweet potatoes; oppositely, it restricted suberization during wound healing at high temperature, which might be related

Table 3 Effect of different growth regulators combined with curing on the iodine staining and the sprouting rate of the sweet potato healed at $29^{\circ} \mathrm{C} \mathrm{RH} 90 \%$ for $4 \mathrm{~d}$ and then storage for $25 \mathrm{~d}$ at $(\mathbf{2 5} \pm 0.5)^{\circ} \mathrm{C}$

\begin{tabular}{lcc}
\hline \multicolumn{1}{c}{ Treatments } & Iodine staining & Sprouting rate/\% \\
\hline Control (without curing) & 0 & 0 \\
Curing & 3, & $82.27 \pm 5.74 \mathrm{a}$ \\
Curing and ethylene & 3, & $2.38 \pm 2.06 \mathrm{e}$ \\
Curing and 1-MCP & 3, & $36.83 \pm 9.45 \mathrm{c}$ \\
Curing and CIPC & 1, & $21.43 \pm 15.97 \mathrm{~d}$ \\
Curing and ABA & 1, & $54.63 \pm 15.36 \mathrm{~b}$ \\
\hline
\end{tabular}

Note: 0', 1', 2' and 3' mean the extent of sweet potato tubers stained by iodine solution, where 0' represents black blue, 1' represents blue, 2' represents weak blue, and 3' represents no discoloration. The same letters in sprouting rate column mean no significant difference $(p>0.05)$. to the inhibition of endogenous $\mathrm{ABA}$ during root suberization after exogenous ABA application. The present results exhibited that the root sprout was suppressed effectively by exogenous $\mathrm{ABA}$ treatment, which played a similarly role to the plant growth of the root development ${ }^{[27]}$. As a sprouting inhibitor, CIPC has been used widely in potatoes. Even though CIPC could suppress sprouting of sweet potatoes, it restricted the progress of wound healing, which could result in serious decay during long-term storage.

3.7 Inhibitory effect of ethylene, 1-MCP, CIPC and ABA on the decay of the sweet potato

The effect of ethylene on accelerating ripening and senescence of fruits and vegetables has been established. Recently, additional functions of ethylene have been elucidated such as enhancing the resistance of sweet potato against black $\operatorname{rot}^{[30]}$, mediating dormancy and sprout growth ${ }^{[31,32]}$, and reducing chilling injury of the pear fruit $^{[33]}$. On the other hand, studies also show that exogenous ethylene escalated the root decay of the sweet potato ${ }^{[34,35]}$. In this study, compared with curing at $29^{\circ} \mathrm{C}$ for $4 \mathrm{~d}$, 1-MCP could effectively inhibit the decay rate during the storage, but ethylene, CIPC and ABA could accelerate the decay during the storage (Table 4). Moreover, 1-MCP treatment could not restrict wound healing. Therefore, wound healing combined with 1-MCP treatment can better inhibit decay and sprouting of sweet potatoes. It is found that $1-\mathrm{MCP}$ could inhibit the onion bolting ${ }^{[31]}$ and the sweet potato decay ${ }^{[36]}$. Similar results were shown in the present study, indicating that as an ethylene-binding inhibitor, 1-MCP can effectively inhibit senescence of fruits and vegetables and also inhibit sprouting and decay of the sweet potato. Effects of ABA on decay of stored roots haven't been elucidated up to now. The results show $\mathrm{ABA}$ could inhibit sprouting of sweet potato roots but simultaneously accelerate the decay at the later stage of their storage, which may be related to ABA triggering ethylene production then expediting cell senescence ${ }^{[37]}$.

Table 4 Effect of different growth regulators combined with curing on decay rate of the sweet potato after cured for $4 \mathrm{~d}$ then stored at $(\mathbf{1 3} \pm \mathbf{0 . 5})^{\circ} \mathrm{C}$ for different months

\begin{tabular}{|c|c|c|c|c|}
\hline \multirow{2}{*}{ Treatments } & \multicolumn{4}{|c|}{ Decay rate at different storage months $/ \%$} \\
\hline & 3 & 5 & 7 & 9 \\
\hline Curing & $2.38 \pm 2.06^{\mathrm{c}}$ & $15.26 \pm 2.11^{\mathrm{c}}$ & $29.36 \pm 5.54^{\mathrm{c}}$ & $46.63 \pm 4.66^{\mathrm{c}}$ \\
\hline Curing combined with ethylene & $5.00 \pm 3.54^{\mathrm{b}}$ & $32.00 \pm 7.07^{\mathrm{a}}$ & $49.00 \pm 7.67^{\mathrm{a}}$ & $67.00 \pm 8.23^{\mathrm{a}}$ \\
\hline Curing combined with 1-MCP & $0.00 \pm 0.00^{\mathrm{c}}$ & $0.00 \pm 0.00^{\mathrm{d}}$ & $2.12 \pm 1.10^{\mathrm{d}}$ & $10.21 \pm 2.15^{\mathrm{d}}$ \\
\hline Curing combined with CIPC & $13.65 \pm 1.69^{\mathrm{a}}$ & $20.42 \pm 4.88^{\mathrm{c}}$ & $38.88 \pm 10.33^{\mathrm{bc}}$ & $58.56 \pm 9.09^{\mathrm{b}}$ \\
\hline Curing combined with ABA & $5.56 \pm 2.41^{\mathrm{b}}$ & $30.33 \pm 6.72^{\mathrm{ab}}$ & $42.21 \pm 5.20^{\mathrm{b}}$ & $65.33 \pm 5.89^{\mathrm{ab}}$ \\
\hline
\end{tabular}

Note: The same letters in one column mean no significant difference $(p>0.05)$.

\section{Conclusions}

Wound healing is a key step for reducing decay of the sweet potato before its long-term storage. A new method of iodine dye for identifying wound healing was developed. The proposed method was easy to discern whether the wounds of roots were healed well or not. Wound healing helped the sweet potato maintain higher reducing sugar content and antioxidant capacity and lower starch content during storage. In addition, continuous ethylene or 1-MCP treatment could effectively suppress the sprouting of the sweet potato and had no negative effect on wound healing simultaneously. And 1-MCP treatment can effectively inhibit root sprouting and decay rate during curing and the subsequent long-term storage.

\section{Acknowledgements}

This work was supported by the project of Potato Industry Innovation Team for Modern Agricultural Industry Technology System, Shandong Province, China (Grant No. SDAIT-16-11) and Funds of Shandong "Double Tops" Program (Grant No. SYT2017XTTD04).

\section{[References]}

[1] Hermes D, Dudek D N, Maria M D, Horta L P, Lima E N, Fátima A D, et al. In vivo wound healing and antiulcer properties of white sweet potato (Ipomoea batatas). Journal of Advanced Research, 2013; 4: 411-415.

[2] Lien C Y, Lee A Y F, Chan C F, Lai Y C, Huang C L, Liao W C. Extraction parameter studies for anthocyanin extraction from purple sweet potato variety TNG73, Ipomoea btatas L. Applied Engineering in 
Agriculture, 2010; 26: 441-446.

[3] Vimala B, Nambisan B, Hariprakash B. Retention of carotenoids in orange-fleshed sweet potato during processing. Journal of Food Science and Technology, 2011; 48: 520-524

[4] Essilfie M E, Dapaah H K, Ofosu-Anim J, Blay E T, Norman J C. Effect of different storage methods and fertilizer rates on quality of sweet potato (Ipomoea batatas L.) storage roots. International Journal of Plant \& Soil Science, 2016; 10(1): 1-12.

[5] Atuna R A, Carey E E, Low J W, Amagloh F K. Wound healing and dry matter content of orange-fleshed sweetpotato cultivars as influenced by curing methods. Open Agriculture, 2017; 2(1): 274-279.

[6] Leonard L M, Louis K M. Wound healing, keeping quality, and compositional changes during curing and storage of sweet potatoes. Hilgardia, 1955; 24: 143-183.

[7] Jensen W A. Botanical histochemistry: Principles and practice. San Francisco: Freeman, 1962.

[8] Oirschota Q E A V, Reesa D, Akedb J, Kihurani A. Sweetpotato cultivars differ in efficiency of wound healing. Postharvest Biology and Technology, 2006; 42(1): 65-74.

[9] Edmunds B, Boyette M, Clark C, Ferrin D, Smith T, Holmes G. Postharvest handling of sweetpotatoes. Raleigh: North Carolina Cooperative Extension Service (US), 2008.

[10] Kushman L J, Wright F S. Sweet potato storage. In: USDA Agriculture Handbook. Washington DC: USDA, 1969; 358p.

[11] Cools K, Chope A G, Hammond J P, Thompson A J, Terry L A. Ethylene and 1-methylcyclopropene differentially regulate gene expression during onion sprout suppression. Plant Physiology, 2011; 156: 1639-1652.

[12] Foukaraki S G, Cools K, Terry L A. Differential effect of ethylene supplementation and inhibition on abscisic acid metabolism of potato (Solanum tuberosum L.) tubers during storage. Postharvest Biology and Technology, 2016; 112: 87-94

[13] Walter W M, Schadel J, Schadel W E. A rapid method for evaluating curing progress in sweet potatoes. Journal of the American Society for Horticultural Science, 1982; 107(6): 1129-1133.

[14] Ji H, Zhang H, Li H, Li Y. Analysis on the nutrition composition and antioxidant activity of different types of sweet potato cultivars. Food and Nutrition Sciences, 2015; 6: 161-167.

[15] Dandago M A, Gungula D T. Effects of various storage methods on the quality and nutritional composition of sweet potato (Ipomoea batatas L.) in Yola Nigeria. International Food Research Journal, 2011; 18: 271-278.

[16] Dong T, Shi J, Jiang C Z, Feng Y, Cao Y, Wang Q. A short-term carbon dioxide treatment inhibits the browning of fresh-cut burdock. Postharvest Biology and Technology, 2015; 110: 96-102.

[17] Nnodu E C, Harrison M D, Parke R V. The effect of temperature and relative humidity on wound healing and infection of potato tubers by Alternaria solani. American Journal of Potato Research, 1982; 59(7): 297-311.

[18] Rees D, Van-Oirschot Q E A, Amour R, Rwiza E, Kapinga R, Carey T. Cultivar variation in keeping quality of sweetpotatoes. Postharvest Biology and Technology, 2003; 28: 313-325.

[19] Rees D, Van-Oirschot Q E A, Aked J. The role of carbohydrates in wound-healing of sweet potato roots at low humidity. Postharvest Biology and Technology, 2008; 50: 79-86.

[20] de Albuquerque T M R, Sampaio K B, de Souza E L. Sweet potato roots: unrevealing an old food as a source of health promoting bioactive compounds - A review. Trends in Food Science and Technology, 2019: 85: 277-286.

[21] Oki T, Masuda M, Furuta S, Nishiba Y, Terahara N, Suda I. Involvement of anthocyanins and other phenolic compounds in radical-scavenging activity of purple-fleshed sweet potato cultivars. Journal of Food Science, 2002; 67: 1752-1756

[22] Konczak-Islam I, Yoshimoto M, De X H, Terahara N, Yamakawa O Potential chemopreventive properties of anthocyanin-rich aqueous extracts from in vitro produced tissue of sweetpotato (Ipomoea batatas L.). Journal of Agricultural and Food Chemistry, 2003; 51: 5916-5922.

[23] Cingoz G S, Verma S K, Gurel E. Hydrogen peroxide-induced antioxidant activities and cardiotonic glycoside accumulation in callus cultures of endemic digitalis species. Plant Physiology \& Biochemistry, 2014; 82(3): 89-94.

[24] Grace M H, Yousef G G, Gustafson S J, Truong V, Yencho G C, Lila M A Phytochemical changes in phenolics, anthocyanins, ascorbic acid, and carotenoids associated with sweetpotato storage and impacts on bioactive properties. Food Chemistry, 2014; 145: 717-724.

[25] Cheema M U A, Rees D, Colgan R J, Taylor M, Westby A. The effects of ethylene, 1-MCP and AVG on sprouting in sweetpotato roots. Postharvest Biology and Technology, 2013; 85: 89-93.

[26] Lulai E C, Suttle J C. The involvement of ethylene in wound-induced suberization of potato tuber (Solanum tuberosum L.): a critical assessment. Postharvest Biology and Technology, 2004; 34(1): 105-112.

[27] Jarret R L, Gawel N. Abscisic acid-induced growth inhibition of sweet potato (Ipomoea batatas L.) in vitro. Plant Cell, Tissue and Organ Culture, 1991; 24: 13-18

[28] Han X, Mao L, Wei X, Lu W. Stimulatory involvement of abscisic acid in wound suberization of postharvest kiwifruit. Scientia Horticulturae, 2017; 224: 244-250.

[29] Han X, Mao L, Lu W, Tao X, Wei X, Luo Z. Abscisic acid induces differential expression of genes involved in wound-induced suberization in postharvest tomato fruit. Journal of Integrative Agriculture, 2018; 17(12): 2670-2682.

[30] Stahmann M A, Clare B G, Woodbury W. Increased disease resistance and enzyme activity induced by ethylene and ethylene production by black rot infected sweet potato tissue. Plant Physiology, 1966; 41(9): 1505-1512.

[31] Downes K, Chope G A, Terry L A. Postharvest application of ethylene and 1-methylcyclopropene either before or after curing affects onion (Allium cepa L.) bulb quality during long term cold storage. Postharvest Biology and Technology, 2010; 55(1): 36-44.

[32] Foukaraki S G, Cools K, Chope G A, Terry, L A. Impact of ethylene and 1-MCP on sprouting and sugar accumulation in stored potatoes. Postharvest Biology and Technology, 2016; 114: 95-103.

[33] Ma Y, Yang M, Wang J, Jiang C Z, Wang Q. Application of exogenous ethylene inhibits postharvest peel browning of 'Huangguan' pear. Frontiers in Plant Science, 2017; 7: 2029. doi: 10.3389/fpls.2016.02029.

[34] Amoah R S, Landahl S, Terry L A. The timing of exogenous ethylene supplementation differentially affects stored sweetpotato roots. Postharvest Biology and Technology, 2016; 120: 92-102.

[35] Arancibia R A, Main L J, Clark C A. Sweet potato tip rot incidence is increased by preharvest applications of ethephon and reduced by curing. Hort Technology, 2013; 23(3): 288-293.

[36] Amoah R S, Terry L A. 1-Methylcyclopropene (1-MCP) effects on natural disease resistance in stored sweet potato. Journal of the Science of Food and Agriculture, 2018; 98: 4597-4605.

[37] Soto A, Ruiz K B, Ravaglia D, Costa G, Torrigiani P. ABA may promote or delay peach fruit ripening through modulation of ripening- and hormone-related gene expression depending on the developmental stage. Plant Physiology and Biochemistry, 2013; 64(5): 11-24. 